\title{
FORMULASI DAN UJI HEDONIK SERBUK JAMU INSTAN ANTIOKSIDAN BUAH NAGA SUPER MERAH (HYLOCEREUS COSTARICENSIS) DENGAN PEMANIS ALAMI DAUN STEVIA (STEVIA REBAUDIANA BERTONI M.)
}

\author{
Indri Kusuma Dewi, Titik Lestari \\ Kementerian Kesehatan Politeknik Kesehatan Surakarta Jurusan Jamu
}

\begin{abstract}
Jamu Instant Powder, Dragon Fruit Super Red, Stevia, Physical Test, Antioxidant, Hedonic. Dragon fruit super red has antioxidant activity, so dragon fruit super red formulated in jamu instant powder dosage form because can be usefull to society without brewing before with natural sweetener stevia leaf. The aim of this research to know formulation jamu instant powder dosage form antioxidant dragon fruit super red with natural sweetener stevia leaf and hedonic test and test of antioxidant activity. This study was descriptive study and laboratory design. The evaluation included physical test is water content, flowability time, angel of repose, uniformity of weight, organoleptic dan $\mathrm{pH}$; antioxidant activity with IC50 parameters, hedonic measurement with hedonic scale. The result showed physical test jamu instant powder included water content 1,85\%; flowability time 35,97 second; angel of repose $37,34^{\circ}$, uniformity of weight 1,01775 gram, organoleptic is purplish red of colour, unpleasant odour, soft of textur dan sweet of taste; and result of $\mathrm{pH} \mathrm{4,47.} \mathrm{The} \mathrm{result}$ measurement antioxidant activity had coverage categories antioxidant activity with IC50 at 132,125 ppm. Hedonic test results of colour indicators 63,3\% of respondents are very like, from the colour indicators $46,7 \%$ of the respondents are did not like, from the taste indicators $46,7 \%$ of the respondent are like, while texture indicators $50 \%$ are like.
\end{abstract}

Keywords : Jamu Instant Powder, Dragon Fruit Super Red, Stevia, Physical Test, Antioxidant, Hedonic

\begin{abstract}
Abstrak : Serbuk Jamu Instan, Buah Naga Super Merah, Stevia, Uji Fisik, Antioksidan, Hedonik. Buah naga super merah mempunyai aktivitas sebagai antioksidan, maka buah naga diformulasi dalam bentuk serbuk jamu instan karena dapat dimanfaatkan masyarakat tanpa menyeduh terlebih dahulu dengan pemanis alami yaitu daun stevia. Penelitian ini untuk mengetahui formulasi serbuk jamu instan antioksidan buah naga super merah dengan pemanis alami daun stevia dan uji hedoniknya serta untuk menguji kemampuan aktivitas antioksidan. Penelitian ini merupakan penelitian laboratorium dengan rancangan penelitian deskriptif. Pengujian meliputi uji fisik yaitu kadar air, waktu alir, sudut diam, keseragaman bobot, organoleptik dan $\mathrm{pH}$; uji antioksidan dengan parameter IC50, uji hedonik dengan hedonic scale. Hasil penelitian untuk uji fisik serbuk jamu instan yaitu kadar air 1,85\%; waktu alir 35,97 detik; sudut diam $37,34^{\circ}$, keseragaman bobot 1,01775 gram, hasil organoleptik berupa warna merah keunguan, bau langu, tekstur serbuk lembut dan rasa manis; serta nilai $\mathrm{pH} 4,47$. Hasil uji antioksidan mempunyai nilai IC50 sebesar 132,125 ppm dengan kategori sedang. Hasil uji hedonik dari indikator warna sebanyak 63,3\% responden meyatakan sangat
\end{abstract}


suka, indikator aroma sebanyak $46,7 \%$ responden menyatakan tidak suka, indikator rasa sebanyak $46,7 \%$ responden menyatakan suka, indikator tekstur sebanyak $50 \%$ responden menyatakan suka.

Kata Kunci : Serbuk Jamu Instan, Buah Naga Super Merah, Stevia, Uji Fisik, Antioksidan, Hedonik

\section{PENDAHULUAN}

Secara alamiah dalam kehidupan sehari-hari, tubuh manusia tidak terlepas dari paparan radikal bebas yang bisa memicu penuaan dini. Faktor penyebab penuaan dini yang paling sering diungkapkan adalah teori senyawa radikal bebas (Kosasih, dkk., 2006). Radikal bebas adalah molekul yang memiliki satu atau lebih elektron yang tidak berpasangan. (Pietta, 1999; Wijaya, 1996). Antioksidan berperan dalam menetralisir atau menangkap radikal bebas sehingga menghambat proses penuaan dan mencegah terjadinya kerusakan tubuh dari timbulnya penyakit degeneratif (Kosasih, dkk., 2006).

Buah naga super merah mempunyai kandungan vitamin $\mathrm{C}$ dan karoten yang diduga sebagai antioksidan dan berdasarkan penelitian terbukti bahwa buah naga super merah mempunyai aktivitas sebagai antioksidan dilakukan dengan menggunakan DPPH atau Difenilpikril Hidrazil Hidrat sebagai radikal bebas yang stabil. Berdasarkan data hasil pengujian aktivitas antiradikal bebas tersebut, menunjukkan bahwa dengan ekstrak air buah naga super merah dengan konsentrasi 4,49\% (setara dengan $15,4 \mathrm{~g}$ buah naga segar) mempunyai kapasitas peredaman atau mempunyai aktivitas antioksidan terbesar yakni 87,11 $\%$ (Umayah,E. \& Moch.A., 2007).

Adanya khasiat buah naga super merah sebagai antioksidan yang sudah terbukti tersebut, maka buah naga super merah selanjutnya diformulasi dalam bentuk sediaan serbuk jamu instan karena dapat dimanfaatkan masyarakat secara praktis tanpa menyeduh atau merebus terlebih dahulu. Serbuk jamu instan dikenal oleh masyarakat dengan rasanya yang pahit, sehingga dalam pembuatannya ditambahkan pemanis alami yaitu daun stevia untuk meningkatkan kualitas rasa. Resiko yang ditimbulkan dengan penggunaan pemanis buatan yang cukup serius sehingga lebih aman bila menggunakan pemanis alami. Daun stevia, digunakan sebagai pemanis alami dan diketahui memiliki kemampuan antioksidan.

Sampai saat ini belum diketahui formulasi yang tepat untuk pembuatan serbuk jamu instan buah naga super merah dengan pemanis alami daun stevia dan perlu dilakukan uji kesukaan (hedonik) yang berupa tanggapan pribadi yaitu berupa kesan yang berhubungan dengan kesukaan atau tanggapan senang atau tidaknya terhadap sifat sensori atau kualitas yang dinilai (Rahardjo, 1998 dalam Rahmadhani, et al, 2012). Oleh sebab itu, perlu dilakukan penelitian ini sehingga didapatkan serbuk jamu instan dengan uji fisik yang baik, uji kesukaan serta uji sebagai antioksidan.

\section{METODE PENELITIAN}

Jenis penelitian yang akan dilakukan adalah eksperimental kuantitatif dengan One shot case study. Pertama, 
formulasi serbuk jamu instan antioksidan buah naga adalah proses pembuatan sediaan berupa serbuk dari bahan aktif berupa buah naga dengan bahan tambahan pemanis alami daun stevia yang sudah memenuhi standar mutu kadar airnya serta bahan tambahan lainnya secara metode pengeringan spray dryer.

\section{Tabel 1}

Formula Serbuk Jamu Instan

\begin{tabular}{|c|c|c|}
\hline Bahan & Formula & Fungsi \\
\hline $\begin{array}{l}\text { Ekstrak Buah } \\
\text { naga segar }\end{array}$ & $\begin{array}{l}15,4 \\
\text { gram }\end{array}$ & $\begin{array}{l}\text { Zat aktif } \\
\text { (sebagai } \\
\text { antioksidan) }\end{array}$ \\
\hline $\begin{array}{l}\text { Serbuk daun } \\
\text { stevia }\end{array}$ & $\begin{array}{l}0,09 \\
\text { gram }\end{array}$ & $\begin{array}{l}\text { Bahan } \\
\text { pemanis alami }\end{array}$ \\
\hline Maltodekstrin & $\begin{array}{l}4,65 \\
\text { gram }\end{array}$ & Bahan pengisi \\
\hline Gom Arab & $\begin{array}{l}1,77 \\
\text { gram }\end{array}$ & $\begin{array}{l}\text { Bahan } \\
\text { pengikat }\end{array}$ \\
\hline Aquadest & q.s. & Pelarut \\
\hline
\end{tabular}

Kedua, uji fisik serbuk jamu instan buah naga super merah adalah pengujian untuk mengevaluasi produk serbuk jamu instan buah naga super merah sesuai dengan parameter mutu. Uji fisik ini meliputi:

a. Uji kadar air adalah persentase air yang terkandung dalam serbuk dengan mouisture balance.

b. Uji waktu alir serbuk adalah hasil penghitungan waktu yang dibutuhkan serbuk untuk mengalir sampai habis. Waktu alir granul dihitung dalam detik. Sedangkan uji sudut diam adalah hasil pengukuran sudut yang dibentuk oleh tumpukan serbuk terhadap bidang datar setelah serbuk tersebut mengalir secara bebas melalui celah sempit.

c. Uji keseragaman bobot adalah hasil penghitungan pembagian serbuk sama rata tanpa menimbangnya.

d. Uji organoleptik adalah hasil pengujian formulasi serbuk jamu instan antioksidan buah naga dengan menggunakan panca indera. Penilaian uji organoleptik berupa warna, aroma, tekstur dan rasa.

e. Uji $\mathrm{pH}$ adalah hasil pengukuran tingkat keasaman suatu serbuk dengan pHmeter.

Keempat, uji hedonik merupakan uji untuk mengetahui tingkat kesukaan terhadap produk minuman jamu instan yang terdiri dari warna, aroma, tekstur, dan rasa. Penilaian uji hedonic scale didapat dengan nilai 1 sampai dengan 4 dengan responden Mahasiswa Jurusan Jamu Poltekkes Surakarta Semester II sebanyak 30 responden.

Analisis data penelitian ini menggunakan analisis univariate untuk menggambarkan hasil uji fisik, uji hedonik dan uji antioksidan dalam bentuk tabel distribusi frekuensi.

\section{HASIL PENELITIAN}

Uji organoleptik meliputi pengamatan warna, bau,rasa serta tekstur pada serbuk minuman jamu instan dengan menggunakan panca indera.

\section{Tabel 2}

\section{Hasil Uji Organoleptik Serbuk Jamu}

Instan Buah Naga Super Merah dengan Pemanis Alami Daun Stevia

\begin{tabular}{cll}
\hline \multirow{2}{*}{ No } & \multicolumn{2}{c}{ Uji } \\
& Organoleptik & \multicolumn{1}{c}{ Hasil } \\
\hline 1 & Warna & Merah Keunguan \\
2 & Bau & Langu \\
3 & Rasa & Hambar saat pertama \\
& & $\begin{array}{l}\text { pengecapan dan } \\
\end{array}$ \\
& & manis setelah beberapa saat \\
4 & Tekstur & Lembut \\
\hline
\end{tabular}


Uji pH serbuk minuman jamu instan dengan cara melarutkan 8 gram serbuk minuman instan dengan $20 \mathrm{ml}$ air. Dari hasil uji $\mathrm{pH}$ menggunakan $\mathrm{pH}$ meter, $\mathrm{pH}$ yang didapat sebesar 4,47. Hasil uji $\mathrm{pH}$ yang didapatkan harus asam $(\mathrm{pH} 6-$ 6,8) karena mempengaruhi kualitas rasa serbuk (Afifah et al, 2011), ini membuktikan bahwa $\mathrm{pH}$ serbuk minuman jamu instan tidak sesuai standar (basa).

Uji antioksidan sediaan instan buah naga merah dengan pemanis alami stevia dilakukan menggunakan metode DPPH (1,1-diphenyl-2-picrylhydrazyl) dengan alat pengukuran spektrofotometri UV-Vis. Hasil dari pengujian antioksidan sebagai berikut:

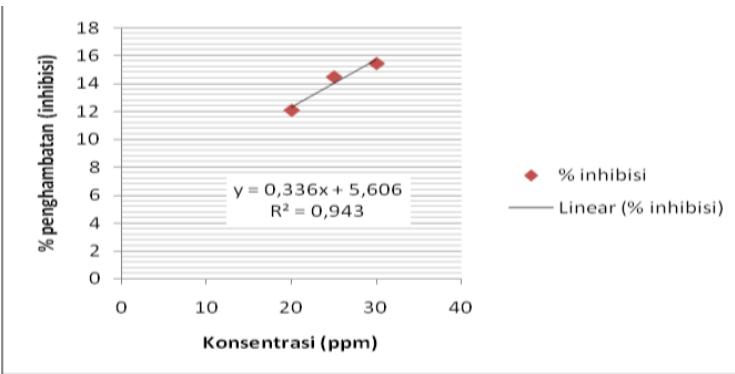

Gambar 5.1. Kurva regresi liner pengujian aktivitas antioksidan instan buah naga

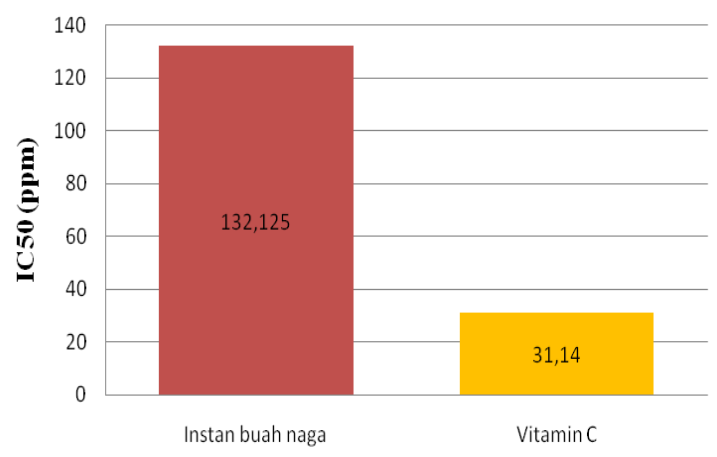

Gambar 5.2. Nilai IC50 instan buah naga dan vitamin $\mathrm{C}$

Berdasarkan data pada gambar di atas, nilai $\mathrm{IC}_{50}$ (Inhibition concentration) sediaan instan buah naga dengan pemanis alami stevia adalah 132,125 ppm termasuk kedalam kategori sedang, sedangkan nilai
$\mathrm{IC}_{50}$ pada pembanding vitamin $\mathrm{C}$ adalah 31,14 ppm termasuk dalam kategori sangat kuat.

Uji hedonik adalah uji untuk mengungkapkan tanggapan pribadi yaitu berupa kesan yang berhubungan dengan kesukaan atau tanggapan senang atau tidaknya terhadap sifat sensori atau kualitas sediaan instan buah naga super merah.

Responden uji hedonik pada penelitian ini adalah mahasiswa Semester 2 Jurusan Jamu Poltekkes Surakarta yang termasuk dalam kategori tidak terlatih berjumlah sebanyak 30 responden. Uji hedonik untuk melihat tingkat kesukaan responden terhadap sediaan instan buah naga super merah berdasarkan masing masing indikator warna, aroma, rasa dan tekstur. Berdasarkan tingkat kesukaan Sangat Tidak Suka (STS), Tidak Suka (TS), Suka (S), Sangat Suka (SS).

\section{Tabel 3}

\section{Hasil Uji Hedonik Sediaan Instan} Ekstrak Buah Naga Super Merah (Hylocereus costaricensis) dengan Pemanis Alami Daun Stevia (Stevia rebaudiana Bertoni M.)

\begin{tabular}{llllll}
\hline \multirow{2}{*}{ No } & Indikator & \multicolumn{3}{c}{ Tingkat Kesukaan } \\
\cline { 3 - 6 } & & \multicolumn{2}{c}{ STS } & \multicolumn{2}{c}{ TS } \\
\cline { 3 - 6 } & & $\mathrm{n}$ & $\%$ & $\mathrm{n}$ & $\%$ \\
\hline 1 & Warna & 0 & 0 & 1 & 3,3 \\
2 & Aroma & 3 & 10 & 12 & 40 \\
3 & Rasa & 3 & 10 & 14 & 46,7 \\
4 & Tekstur & 1 & 3,3 & 9 & 30 \\
\hline
\end{tabular}

Berdasarkan tabel 3 menunjukkan bahwa hasil penelitian serbuk instan buah naga super merah berwarna merah muda dan uji hedonik serbuk instan buah naga super merah berdasarkan indikator warna menunjukkan responden sebanyak 3,3\% menyatakan tidak suka, $33,3 \%$ 
menyatakan suka dan 63,3\% menyatakan sangat suka. Uji hedonik serbuk instan buah naga super merah berdasarkan indikator aroma menunjukkan responden sebanyak $10 \%$ menyatakan sangat tidak suka, 46,6\% menyatakan tidak suka dan $43,3 \%$ menyatakan suka. Hasil uji hedonik serbuk instan buah naga super merah berdasarkan indikator rasa menunjukkan responden sebanyak $10 \%$ menyatakan sangat tidak suka, $40 \%$ menyatakan tidak suka, $46,7 \%$ menyatakan suka dan 3,3\% menyatakan sangat suka. Hasil penelitian serbuk instan buah naga super merah bertekstur halus dan hasil uji hedonik sediaan instan buah naga super merah berdasarkan indikator tekstur menunjukkan responden sebanyak 3,3\% menyatakan sangat tidak suka, 30\% menyatakan tidak suka, 50\% menyatakan suka dan $16,7 \%$ menyatakan sangat suka.

\section{PEMBAHASAN}

Kadar air yang didapat dari hasil pengujian kadar air serbuk minuman jamu instan pada penelitian ini adalah 1,87\%, kadar air dalam penelitian ini sesuai termasuk standar serbuk instan yang baik yaitu kurang dari 3\%. Hal ini menunjukkan bahwa tingginya kandungan lembab pada serbuk minuman jamu instan hasil penelitian Mohrle (1989) dalam Anam (2013) menyatakan bahwa kelembaban udara dalam ruang yang tinggi menyebabkan serbuk menyerap lembab dari lingkungan sehingga serbuk jamu instan yang dihasilkan memiliki kelembaban yang tinggi. Selain itu penambahan bahan pengisi atau bahan tambahan laennya juga mempengaruhi hasil dari kadar air sediaan.

Kadar air yang rendah dan memenuhi standar juga disebabkan oleh penggunaan spray dryer dengan suhu yang tepat yaitu $1000 \mathrm{C}$ selama 32 jam sebagai alat untuk pembuatan serbuk minuman jamu instan, selain itu penambahan maltodekstrin juga sangat berpengaruh dalam pembuatan serbuk instan, dalam penelitian yang dilakukan oleh Stevanus (2013) menunjukan bahwa semakin banyak maltodekstrin yang digunakan, semakin rendah kadar air yang akan didapat.

Sifat alir yang dihasilkan dari sediaan serbuk minuman jamu instan yang didapatkan hasil kecepatan alir dan sudut diam serbuk. Uji kecepatan alir serbuk minuman jamu instan adalah 36 detik. Anshory (2007) menyebutkan bahwa persyaratan waktu alir yaitu tidak lebih dari 10 detik, maka serbuk jamu instan tersebut memiliki waktu alir yang tidak baik. Menurut Anwar (2010) waktu alir dipengaruhi oleh bentuk, ukuran, porositas, densitas, gaya elektrostatika dan gaya gesek partikel serta kondisi percobaan. Selain itu, penggunaan gom sebagai bahan pengikat sangat mempengaruhi waktu alir serbuk karena gom menyebabkan serbuk menjadi mudah lengket. Sudut diam formula minuman jamu instan adalah $37,34^{\circ}$, maka dapat disimpulkan bahwa serbuk minuman jamu instan memiliki sudut diam yang baik. Wadke dan Jacobson (1980) menyebutkan bahwa granul akan mengalir dengan baik jika mempunyai sudut diantara $25-45^{\circ}$. Besar kecilnya sudut yang terbentuk sangat dipengaruhi oleh gaya tarik dan gaya gesekan antar partikel.

Uji keseragaman bobot serbuk jamu instan adalah 4,90 \% tiap dua bungkus serbuk dan 6,90 \% tiap 18 bungkus serbuk. Dalam Farmakope Indonesia IV disebutkan bahwa penyimpangan antara penimbangan satu per satu, terhadap bobot isi rata-rata tidak 
lebih dari $15 \%$ tiap dua bungkus dan tidak lebih dari $10 \%$ tiap 18 bungkus, ini membuktikan bahwa serbuk jamu instan adalah serbuk yang mudah dibagi karena memiliki keseragaman bobot yang baik, karena serbuk tersebut memiliki tingkat kehalusan yang sangat tinggi, memiliki kadar air yang rendah sehingga tidak lembab dan menjadikan serbuk mudah untuk dibagi. Jadi, erbuk jamu instan buah naga super merah memenuhi standar mutu serbuk pada Farmakope Indonesia IV.

Uji organoleptik pada serbuk jamu instan buah naga super merah ini dengan menggunakan panca indera untuk mendeskripsikan tekstur, warna, bau, dan rasa. Terlihat serbuk minuman jamu instan memiliki warna merah keunguan, aroma atau bau langu, tekstur serbuk yang sangat lembut seperti serbuk susu instan dan rasa condong pada rasa yang hambar pada pengecapan pertama dan terasa manis pada pengecapan kedua atau beberapa saat setelah dirasakan.

Warna merah keunguan pada serbuk minuman jamu instan disebabkan karena warna merah alami dari buah naga super merah. Warna merah pada buah naga super merah ini disebabkan oleh banyaknya kandungan fenolat dalam buah tersebut, ini didukung dengan adanya hasil riset Agricultural Risearch Service (ARS) buah naga merah mengandung total fenolat $1.076 / \mathrm{mol}$ gallic acid equivalens(GAE)/ g puree, sedangkan buah naga berdaging putih hanya 523 saja.

Hasil penelitian uji hedonik serbuk jamu instan buah naga super berdasarkan indikator warna sebanyak 63,3\% responden menyatakan sangat suka terhadap warna merah muda dari sediaan instan buah naga super merah. Serbuk jamu instan buah naga seper merah diformulasi dengan penambahan maltodekstrin sehingga didapatkan hasil warna merah muda. Menurut penelitian Yuliawaty dan Susanto (2015), menyatakan bahwa pemberian perlakuan konsentrasi maltodekstrin memberikan pengaruh nyata terhadap nilai kecerahan minuman instan daun mengkudu. Hal ini dikarenakan proporsi penambahan konsentrasi maltodekstrin yang ditambahkan semakin banyak maka derajat kecerahan warna juga semakin tinggi.

Maltodekstrin memiliki warna yang cenderung putih sehingga saat dicampurkannya dengan ekstrak daun mengkudu yang berwarna hijau pekat akan memberikan warna yang cerah dengan banyaknya proporsi maltodekstrin yang ditambahkan maka tingkat kecerahan minuman instan daun mengkudu juga semakin meningkat. Suhu pemanas yang tinggi dapat membuat warna yang terbentuk semakin cerah oleh karena itu dengan penambahan maltodekstrin dan suhu pemanas yang semakin tinggi penampakan minuman serbuk kulit buah manggis cenderung disukai panelis (Putra, 2013). Oleh karena itu, penelitian ini sesuai dengan penelitian sebelumnya.

Menurut penelitian Wahyuni (2012), tentang pemanfaatan buah naga super merah (Hylocereus costaricensis) dalam pembuatan jenang dengan penambahan daging buah yang berbeda, dari hasil penelitian rata-rata nilai kesukaan panelis terhadap aroma jenang buah naga super merah mempunyai nilai terendah 4,65 didapatkan dari perlakuan proporsi penambahan daging buah naga super merah sebesar 50 gram, sedangkan nilai tertinggi 4,85 didapatkan dari perlakuan proporsi penambahan daging buah naga super merah sebesar 10 gram, hal ini dikarenakan semakin banyak 
daging buah naga yang ditambahkan aromanya semakin langu.

Berdasarkan hasil penelitian uji hedonik serbuk jamu instan buah naga super merah didapatkan hasil serbuk halus dengan tingkat kesukaan sebanyak 50\% mengatakan suka dari 30 responden. Formulasi serbuk jamu instan buah naga super merah yaitu ekstrak buah naga dengan pemanis stevia dan bahan tambahan maltodekstrin sebanyak 121 gram dan gom arab 200 gram menggunakan spray dryer dengan suhu 1400 C. Menurut Renkell, et al. (1987) dalam Rony (2008), metode pengeringan yang paling umum digunakan dalam proses pembuatan bubuk instan adalah dengan menggunakan alat pengering semprot (spray dryer). Menurut Voigt (1994) dalam Roni (2008), produk yang dihasilkan dari proses pengeringan semprot berupa serbuk halus yang berukuran 100-200 $\mu \mathrm{m}$.

\section{KESIMPULAN DAN SARAN}

Berdasarkan hasil analisis yang telah didapat untuk formula serbuk jamu instan buah naga super merah didapatkan kesimpulan sebagai berikut:

1. Hasil uji fisik kadar air serbuk jamu instan antioksidan buah naga super merah adalah $1,85 \%$

2. Hasil uji fisik waktu alir serbuk jamu instan antioksidan buah naga super merah adalah 35,97 detik, dengan sudut diam adalah 37,34o

3. Hasil uji fisik keseragaman bobot serbuk jamu instan antioksidan buah naga super merah adalah 1,01775 gram dengan penyimpangan $4,90 \%$ tiap 2 bungkus dan $6,90 \%$ tiap 18 bungkus.
4. Hasil uji fisik organoleptik serbuk jamu instan antioksidan buah naga super merah adalah warna merah keunguan, bau yang langu, tekstur serbuk lembut dan rasa yang dihasilkan hambar pada pengecapan pertama dan mulai terasa manis setelah pengecapan kedua.

5. Hasil uji fisik $\mathrm{pH}$ serbuk jamu instan antioksidan buah naga super merah adalah sebesar 4,47.

6. Hasil uji antioksidan serbuk jamu instan buah naga super merah mempunyai nilai IC50 sebesar 132,125 ppm dengan kategori sedang.

7. Hasil uji hedonik serbuk instan buah naga super merah dari indikator warna sebanyak $63,3 \%$ responden meyatakan sangat suka, indikator aroma sebanyak 46,6\% responden menyatakan tidak suka, indikator rasa sebanyak $46,7 \%$ responden menyatakan suka, indikator tekstur sebanyak 50\% responden menyatakan suka.

8. Bahan tambahan untuk membuat serbuk minuman jamu instan harus tepat supaya serbuk tidak mudah lengket dan memberikan aroma yang lebih baik.

9. Perlu tempat khusus untuk penyimpanan serbuk minuman jamu instan karena sangat mudah lembab dan menjadi keras.

10. Penentuan formulasi yang tepat dalam pembuatan serbuk minuman jamu instan agar rasa yang dihasilkan lebih enak dan lebih mudah untuk disimpan.

11. Proses pembuatan sediaan instan dilakukan dengan suhu dan teknik metode yang tepat agar pada saat 
proses pembuatan buah tidak rusak.

12. Perlu dilakukan penelitian lebih lanjut untuk mencari teknik pembuatan sediaan instan yang lebih baik agar mendapat tekstur yang lebih tahan lama dalam proses penyimpanan.

13. Perlu dilakukan uji antioksidan dengan metode yang berbeda seperti metode diena terkonjugasi, FRAP (ferric reducing antioxidant power), CUPRAC (cupric ion reducing antioxidant capacity) dan ABTS (Asam 2,2-Azinobis(3etilbenzatiazolin)-6-sulfonat) agar lebih akurat untuk mengetahui aktivitas antioksidan yana terkandung.

14. Melakukan rancangan formula yang bervariasi dan cara pembuatan sediaan instan yang lebih tepat agar menghasilkan sediaan instan yang sempurna.

15. Perlu dilakukan penelitian lanjutan mengenai penentuan jenis senyawa antioksidan misalnya flavonoid pada sediaan instan buah naga merah dengan pemanis alami daun stevia.

\section{DAFTAR RUJUKAN}

Anam, C., Kawiji, Setiawan, R.D. 2013. Kajian Karakteristik Fisik dan Sensori Serta Aktivitas Antioksidan dari Granul EffervescentBuah Beet (Beta Vulgaris) dengan Perbedaan Metode Granulasi dan Kombinasi Sumber Asam. Jurnal Teknologi Hasil Pertanian 2(2):21-27

Anshory, H., Syukri, Y., dan Malasari, Y. 2007. Formulasi Tablet Effervescent Dari Ekstrak Ginseng
Jawa (Talinum Paniculatum) Dengan Variasi Kadar Pemanis Aspartam. Jurnal Ilmiah Farmasi Vol.4 No.1

Anwar, Khoerul. 2010. Formulasi Sediaan Tablet effervescent Dari Ekstrak Kunyit (Curcuma domestica Val.) Dengan Variasi Jumlah Asam Sitrat-Asam Tartrat Sebagai Sumber Asam. Sains dan Terapan Kimia, Vol 4 No.2 168-178

Afifah,et.al, 2011. Rancangan Proses Produksi Minuman Instan Skala Industri Kecil dari Empon-empon. Prosiding SnaPP2011 Sains Teknologi. ISSN 2089-3582. Subang.

Kosasih, E.N., Tony S. dan Hendro H. 2006. Peran Antioksidan pada Lanjut Usia. Pusat Kajian Nasional Masalah Lanjut Usia. Jakarta

Pietta P-G., 1999. Flavonoids as Antioxidants, Reviews, J. Nat. Prod., 63, 1035-1042.

Putra, S. D. R., 2013. Kualitas Minuman Serbuk Instan Kulit Buah Manggis (Garcinia mangostana Linn.) dengan Maltodekstrin dan Suhu Pemanasan. Skripsi. Yogyakarta: Universitas Atma Jaya Yogyakarta.

Rahmadhani, S., Theo, R. F., Nombiga, T. E., 2012. Uji Penerimaan (Uji Hedonik dan Uji Mutu Hedonk). Bogor: Institut Pertanian Bogor.

Rony,M.A., 2008, Formulasi Minuman Herbal Instan Antioksidan dari Campuran Teh Hijau (Camellia Sinensis), Pegagan (CentellaAsiatica), dan Daun Jeruk Purut (Citrus Hystrix),Skripsi, Institut Pertanian Bogor, Bogor 